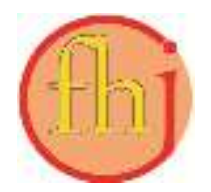

Faletehan Health Journal, 7 (3) (2020) 155-161

www. journal.Ippm-stikesfa.ac.id/ojs/index.php/FHJ

ISSN 2088-673X | e-ISSN 2597-8667

\title{
Pengaruh Senam GITA terhadap IMT dan HbA1C Pada Lansia dengan Diabetes Melitus
}

\author{
Anindini Winda Amalia ${ }^{1 *}$, Paramita Ratna Gayatri ${ }^{2}$, Hartati Tuna ${ }^{3}$ \\ ${ }^{1}$ Prodi D4 Pengobatan Tradisional Tiongkok IIK Bhakti Wiyata Kediri, Indonesia \\ ${ }^{2}$ Prodi S1 Keperawatan IIK Bhakti Wiyata Kediri, Indonesia \\ ${ }^{3}$ Prodi D4 Teknologi Labolatorium Medik IIK Bhakti Wiyata Kediri, Indonesia \\ *Corresponding Author: anindiniwa@gmail.com
}

\begin{abstract}
Abstrak
Latihan fisik telah menjadi regimen terapeutik dalam manajemen diabetes mellitus. Senam GITA adalah latihan fisik yang dapat dilakukan oleh lansia dengan diabetes mellitus dalam mengontrol kadar glukosa darahnya. Tujuan penelitian ini adalah mengetahui pengaruh senam GITA terhadap IMT dan HbA1C pada lansia dengan diabetes mellitus. Penelitian bersifat quasi eksperimen dengan rancangan pre-post control group. Responden merupakan lansia dengan diabetes melitus di Prolanis Kota Kediri. Responden berjumlah 20 orang, terbagi dalam dua kelompok yaitu kelompok senam (10 orang) dan kelompok kontrol (10 orang). Kelompok senam diberikan pelatihan senam GITA selama 12 minggu sebanyak 3 kali dalam seminggu dengan durasi 30 menit setiap sesinya. Sedangkan kelompok kontrol tidak mendapat perlakuan. Hasil penelitian ini menunjukkan IMT kelompok senam signifikan mengalami perubahan dengan $p$ value 0,000001 $(p<0,05)$ dan HbA1C pada kelompok senam mengalami perubahan secara signifikan dengan $p$ value $0,000077(p<0,05)$. Pada uji T terdapat perbedaan signifikan rerata selisih IMT dengan $p$ value $0,000006(p<0,05)$ dan HbA1C dengan $p$ value $0,000006(p<0,05)$ pada kelompok senam dan kelompok kontrol sebelum dan sesudah intervensi. Senam GITA selama 12 minggu efektif dalam mengontrol IMT dan $\mathrm{HbA} 1 \mathrm{C}$ pada lansia dengan diabetes melitus.
\end{abstract}

Kata Kunci: Diabetes Melitus, Lansia, Senam GITA, IMT, HbA1C

\section{Effects of GITA Gymnastics on BMI and HbA1C in Elderly with Diabetes Mellitus}

\begin{abstract}
Physical exercise has become a therapeutic regiment in the management of diabetes mellitus. GITA gymnastics is a physical exercise that can be done by the elderly with diabetes mellitus to control their blood sugar levels. This research is quasi experimental with pre-post control group design. Respondents are elderly with diabetes mellitus in Prolanis, Kediri City. Respondents are 20 people, divided into two groups: gymnastic groups (10 people) and control groups (10 people). The gymnastic group was given GITA training for 12 weeks, 3 times a week, with duration of 30 minutes every session. Meanwhile, the control group wasn't received treatment. The results of this study showed that the gymnastic group experienced a significant BMI change with $p$ value $0.000001(p<0.01)$ and the HbA1C of the gymnastics group experienced a significant change witn $p$ value $0.000077(p<0.05)$. In the $T$-test, there was a significant difference in the mean between $B M I$ with $p$ value $0.000006(p<0.05)$ and $\mathrm{HbA1C}$ with $p$ value $0.000006(p<0.05)$ in the gymnastic group and the control group before and after the intervention. GITA exercise for 12 weeks is effective in controlling BMI and HbA1C in the elderly with diabetes mellitus.
\end{abstract}

Keywords: Diabetes Mellitus, Elderly, GITA gymnastic, BMI, HbA1C 


\section{Pendahuluan}

Keberhasilan pembangunan di sektor kesehatan, telah membuat peningkatan angka harapan hidup. Hal ini mengindikasikan adanya peningkatan jumlah penduduk lansia. Berdasarkan hasil survey BPS tahun 2017, jumlah lansia di Indonesia adalah 23.4 juta (8.97 \%), dengan jumlah lansia wanita $(52.52 \%)$ lebih banyak daripada lansia pria $(47.48 \%)$. Daerah di Indonesia yang memiliki presentase lansia lebih dari sepuluh persen diantaranya: DI Yogyakarta (13.9\%), Jawa Tengah (12.46\%), Jawa Timur (12.16\%), Bali (10.79\%) dan Sualwesi Barat (10.37\%) (BPS, 2017).

Meningkatnya penduduk lansia membawa konsekuensi tersendiri dalam berbagai aspek, termasuk aspek kesehatan. Hal yang perlu diwaspadai dengan peningkatan jumlah lansia adalah meningkatnya jumlah penyakit degeneratif kronis termasuk salah satunya adalah diabetes mellitus (Dwipayanti et al., 2020). Prevalensi diabetes mellitus pada lansia berusia $\geq 65$ tahun adalah sekitar 22-33\%. Diabetes Mellitus pada lansia juga dikaitkan dengan peningkatan komplikasi penyakit baik akut maupun kronis (Kirkman et al., 2012).

Diabetes mellitus (DM) adalah penyakit kronis yang tidak mengakibatkan kematian secara langsung. Namun dapat berakibat fatal bila tidak dilakukan manajemen yang baik. Manajemen diabetes mellitus yang tidak tepat menyebabkan glukosa darah penderita tidak terkontrol dan menyebabkan berbagai kompilkasi seperti diabetik neuropati, diabetik nefropati, stroke, kebutaan, dan ulkus diabetes (Dwipayanti et al., 2020).

Tujuan penatalaksanaan diabetes mellitus dibagi menjadi 3 yaitu: (1) Tujuan jangka pendek yaitu menghilangkan keluhan DM, memperbaiki kualitas hidup, dan mengurangi risiko komplikasi akut; (2) Tujuan jangka panjang yaitu mencegah dan menghambat progresivitas penyulit mikroangiopati dan makroangiopati; (3) Tujuan akhir yaitu turunnya morbiditas dan mortalitas DM. Untuk mencapai tujuan tersebut perlu dilakukan pengendalian glukosa darah, tekanan darah, berat badan dan profil lipid melalui 5 pilar penangan DM. Lima pilar tersebut meliputi edukasi, terapi nutrisi, latihan fisik, terapi farmakologis, dan pemeriksaan kadar gula darah (PERKENI, 2019).Kontrol diabetes mellitus yang tepat dikaitkan dengan penurunan komplikasi diabetes. Hasil Kontrol diabetes dan komplikasi diabetes menunjukkan bahwa kontrol diabetes yang baik dapat mengurangi komplikasi diabetes menjadi kronis antara 20-30\% (American Diabetes Association, 2014). Hasil penelitian dari The United Kingdom Prospective Diabetes Study (UKPDS) menunjukkan bahwa pengurangan 1\% dari nilai $\mathrm{HbA1C}$ akan mengurangi risiko komplikasi sebesar 35\%, mengurangi insiden kematian terkait DM sebesar 21\%, infark miokard sebesar $14 \%$, komplikasi mikrovaskuler sebesar $37 \%$ dan penyakit pembuluh darah perifer sebesar 43\% (Hayes et al., 2013).

Latihan fisik merupakan salah satu pilar dalam penatalaksanaan DM tipe 2. Program latihan fisik secara teratur dapat dilakukan 3-5 kali dalam seminggu dengan durasi 30-45 menit, dengan total 150 menit per minggu. Kegiatan sehari-hari atau aktivitas sehari-hari bukan termasik latihan fisik. Tujuan dari latihan fisik ini selain menjaga kebugaran juga dapat menurunkan berat badan serta memperbaiki sensitivitas insulin sehingga dapat mengontrol kadar gula darah (PERKENI, 2019). Konsumsi obat dalam jangka waktu lama tidak dianjurkan untuk lansia, sehingga salah satu terapi alternatif yang dapat dimaksimalkan dalam penatalaksanaan DM pada lansia adalah latihan fisik. Latihan fisik pada lansia perlu mempertimbangkan aspek keamanan bagi lansia dan mudah dilakukan oleh lansia (Ferriolli et al., 2014).

Senam Gerakan Isyarat Tangan (GITA) merupakan salah satu latihan fisik yang dapat dilakukan lansia dengan diabetes mellitus untuk mengontrol kadar glukosa darahnya. Penelitian (Amalia et al., 2020) diperoleh hasil Senam GITA selama 8 minggu dapat menurunkan kadar gula secara signifikan dengan $p$ value 0.01 . Gerakan pada senam GITA sangat cocok diberikan pada lansia, karena tidak memerlukan gerakan cepat pada senam ini. Hasil analisis kualitatif berdasarkan wawancara semi-terstruktur dari responden yang telah melakukan Senam GITA diperoleh hasil: responden merasa relaks $(60 \%)$, energi meningkat (60\%) dan senam mudah dilakukan (70\%) (Amalia et al., 2020). Senam GITA adalah metode perawatan kesehatan berasal dari Tiongkok dan diperkenalkan oleh Zhi-Chen Guo. Senam GITA terdiri dari serangkaian gerakan dengan teknik penyinaran. Teknik dari gerakan ini dengan meningkatkan atau mengurangi tekanan 
Faletehan Health Journal, 7 (3) (2020) 155-161

www. journal.Ippm-stikesfa.ac.id/ojs/index.php/FHJ

ISSN 2088-673X | 2597-8667

pada bagian tubuh tertentu untuk mengembalikan kembali pergerakan $Q i$ (energi vital) sehingga kondisi tubuh kembali normal dan seimbang (Guo, 2014). Belum banyak penelitian yang meneliti tentang efek senam GITA ini dalam penatalaksanaan diabetes mellitus. Penelitian ini bertujuan mengetahui pengaruh senam GITA terhadap IMT dan HbA1C lansia dengan diabetes mellitus.

\section{Metode Penelitian}

Penelitian ini termasuk jenis penelitian quasy experiment dengan pre-post control grup design. Penelitian dilakukan di Klinik Bandar Lor Kediri pada bulan April - Juli 2020. Penelitian ini telah mendapat pesetujuan etik dari Komite Etik Institut Ilmu Kesehatan Bhakti Wiyata dengan No SK: 1048/PP2M-KE/III/2020. Populasi pada penelitian ini adalah semua lansia dengan diabetes mellitus di Klinik Bandar Lor Kediri. Kriteria inklusi dari penelitian ini adalah usia di atas 60 tahun, mendapat terapi OHO (Obat Hiploglikemia Oral), glukosa darah sewaktu $\geq 200 \mathrm{mg} / \mathrm{dl}$, dapat melalukan aktivitas fisik, bersedia mengikuti penelitian ini dari awal hingga akhir. Kriteria eksklusi penelitian ini adalah responden yang memiliki diabetes mellitus dengan komplikasi penyakit berat antara lain gagal ginjal, penyakit jantung, retinopati, gastropati, baik komplikasi mikrovaskuler ataupun makrovaskuler lainnya.

Total penderita diabetes mellitus di Klinik Bandar Lor berjumlah 93 orang, 46 orang dievaluasi lebih lanjut, dan 20 orang yang memenuhi syarat. Dari 20 orang tersebut kemudian diacak dan dibagi menjadi 2 kelompok yaitu kelompok senam (10 orang) dan kelompok kontrol (10 orang). Pada kelompok senam diberikan pelatihan tentang senam GITA yang dilakukan selama 12 minggu sebanyak 3 kali tiap minggunya. Satu sesi senam GITA berlangsung selama 5 menit gerakan pemanasan, 20 menit gerakan inti, dan 5 menit gerakan pendinginan. Pada kelompok kontrol tidak diberi perlakuan.

Untuk menggurangi bias penelitian, dilakukan pemilihan responden di awal penelitian ini yang memenuhi kriteria inklusi dalam penelitian ini. Responden yang telah dipilih kemudian dibagi menjadi 2 kelompok secara acak serta diukur Indeks Massa Tubuh (IMT) dan kadar HbA1C pada saat sebelum dan sesudah intevensi Senam GITA selama 12 minggu.

\section{Hasil dan Pembahasan}

Karakteristik responden yang terlibat dalam penelitian digambarkan dalam tabel 1 . Berdasarkan Tabel 1 menunjukkan responden terbanyak pada rentang usia 60-69 sebanyak $75 \%$, jenis kelamin terbanyak adalah perempuan sebanyak $60 \%$, pendidikan responden terbanyak pada level menengah sebesar $45 \%$, dan IMT terbanyak responden pada rentang 18.5 - 25.0 sebanyak $55 \%$.

\section{Tabel 1. Distribusi Frekuensi Karakteristik} Responden $(\mathbf{n}=\mathbf{2 0})$

\begin{tabular}{lcc}
\hline \multicolumn{1}{c}{ Variabel } & n & \% \\
\hline Usia & & \\
60-69 tahun & 15 & 75 \\
70-79 tahun & 5 & 25 \\
\hline Jenis Kelamin & & \\
$\quad$ Perempuan & 12 & 60 \\
$\quad$ Laki-laki & 8 & 40 \\
\hline Pendidikan & & \\
Rendah & 6 & 30 \\
Menengah & 9 & 45 \\
Tinggi & 5 & 25 \\
\hline IMT & & \\
18.5-25.0 & 11 & 55 \\
$>25.0$ & 9 & 45 \\
\hline
\end{tabular}

*Sumber: Data Primer (2020)

Pada tabel 1 digambarkan $75 \%$ responden yang mengalamai diabetes mellitus berada pada rentang usia 60-69 tahun. Hal ini sejalan dengan hasil Riskesdas 2018, penderita DM terbanyak di Indonesia berada pada rentang usia 55-64 tahun (6.3\%) dan 65-74 tahun (6\%) (Kemenkes RI, 2018). Proses penuaan megakibatkan tubuh mengalami gangguan homeostasis energi dan kelainan dalam metabolisme karbohidrat. Penyebab terpenting dari hipeglikemia adalah defisiensi sekresi insulin berkembang seiring bertambahnya usia dan meningkatnya resistensi insulin (Mordarska, K.; Godziejewska-Zawada, 2017).

Pada tabel 1 juga menunjukkan data jenis kelamin responden lansia yang mengalami diabetes mellitus terbanyak pada perempuan $(60 \%)$. Hal ini sejalan dengan hasil Riskesdas 2018, penderita DM di Indonesia lebih banyak yang berjenis kelamin perempuan $(1.8 \%)$ daripada laki-laki (1.2\%) (Kemenkes RI, 2018). Wanita menopause menghasilkan lebih sedikit estrogen yang dapat menyebabkan kenaikan dan penurunan kadar 
glukosa yang tidak terduga. Faktor resiko diabetes mellitus yang disebabkan karena obesitas lebih banyak terjadi pada wanita (Kautzky-Willer et al., 2016). Wanita yang memiliki lemak berlebih pada batang tubuh terutama bagian perut, lebih beresiko terkena DM karena lemak pada perut lebih mudah diolah menjadi energi. Pada saat lemak diolah menjadi energi, kadar asam lemak dalam darah meningkat. Tingginya asam lemak dalam darah menyebabkan meningkatnya resistensi terhadap insulin yang berdampak terhadap kejadian diabetes mellitus (Pratiwi et al., 2018).

Pada tabel 1 level pendidikan responden terbanyak berada level menengah. Level pendidikan berpengaruh dengan kejadian diabates mellitus. Pada level pendidikan yang tinggi, akan lebih banyak pengetahuan yang dimiliki dalam menjaga kesehatannya. Peningkatan pengetahuan akan membuat kesadaran dalam menjaga kesehatan meningkat dengan cara hidup sehat, memperbaiki gaya hidup dan pola makan. Pada level pendidikan lebih rendah beresiko tidak memperhatikan gaya hidup dan pola makan untuk mencegah diabetes mellitus (Pahlawati, \& Nugroho, 2019).

Pada tabel 1, Indeks Massa Tubuh terbanyak pada responden berada pada rentang 18.5-25.0 sebanyak 55\%. Kelebihan berat badan / overweight dan obesitas merupakan faktor penyebab komplikasi pada diabetes mellitus tipe dua pada pria maupun wanita. Rentang IMT 2529.99 pada pria maupun wanita meningkatkan resiko perkembangan diabetes mellitus sebesar 1030\%. Pada rentang IMT 30-39.99 meningkatkan resiko DM sebesar 100\%. Pada IMT $\geq 40$ meningkatkan resiko DM pada wanita sebesar $150 \%$ dan $180 \%$ untuk pria (Gray et al., 2015).

Tabel 2. Hasil Rerata Indeks Massa Tubuh Dalam 2 Kelompok Sebelum dan Sesudah Intervensi

\begin{tabular}{ccc}
\hline IMT & Mean+SD & P \\
\hline Senam & & \\
Pretest & $25.18 \pm 1.80$ & 0.000001 \\
Posttest & $24.55 \pm 1.82$ & \\
\hline Kontrol & & \\
Pretest & $25.06 \pm 2.10$ & 0.927 \\
Posttest & $25.05 \pm 2.22$ & \\
\hline
\end{tabular}

SD: Standard Deviation, GDP: Gula Darah Puasa
Tabel 2 menunjukkan hasil pre dan post tes IMT kelompok senam berbeda bermakna secara signifikan dengan $p$ value $0.000001 \quad(\mathrm{p}<0.05)$. Aktivitas fisik yang dilakukan oleh lansia dengan diabetes mellitus berupa senam GITA selama 12 minggu terbukti dapat menurunkan IMT dari $25.18 \pm 1.80$ menjadi $24.55 \pm 1.82 \mathrm{~kg} / \mathrm{m}^{2}$.

Diabetes mellitus memiliki kaitan dengan obesitas. Diperkirakan sekitar $60-90 \%$ pasien diabetes tipe 2 mengalami obesitas (IMT $\geq 30$ $\mathrm{kg} / \mathrm{m}^{2}$ ) dan kelebihan berat badan (overwight) (IMT $\geq 25 \mathrm{~kg} / \mathrm{m}^{2}$ ). Penyimpanan lemak yang berlebihan pada orang obesitas, menyebabkan pelepasan asam lemak yang berlebihan sehingga dapat mengakibatkan resistensi insulin dan hipeglikemia. Resistensi inslulin yang terjadi juga merupakan konsekuensi dari peningkatan sekresi sitokin (TNF- $\alpha$, IL-6, komplemen C3, MIF dan leptin) oleh jaringan adiposa yang mengakibatkan perkembangan diabetes. Perkembangan ini dapat dicegah dengan meningkatkan aktivitas fisik dan menjaga berat badan tetap ideal (Siddiqui, 2018).

Hasil rerata Indeks Massa Tubuh responden di kedua kelompok pada penelitian ini termasuk dalam kategori kelebihan berat badan / overweight (25 > IMT > 27) sesuai dengan kriteria Kemenkes. Pada kelompok senam GITA selama 12 minggu dapat menurunkan IMT secara signifikan dengan $p$ value $<0.01$. Sejalan dengan penelitian yang lain terkait efek senam dalam menurunkan IMT. Penelitian Zhou et al. (2019) menjelaskan salah satu metode senam yaitu Tai Chi juga dapat menurunkan IMT secara signifikan (MD $-0.82 \mathrm{~kg}$ $/ \mathrm{m}^{2} ; 95 \% \mathrm{CI}-1.28$ hingga $-0.37 \mathrm{~kg} / \mathrm{m}^{2} ; \mathrm{p}<0.001$; heterogenitas, $\mathrm{I} 2=26.3 \%, \mathrm{p}=0,228$ ).

Senam GITA merupakan integrasi dari pikiran-tubuh serta pemurnian energi vital yang berguna dalam penyembuhan dengan dirinya sendiri (Guo, 2017). Hal tersebut sejalan dengan metode perawatan kesehatan lain dari Tiongkok yaitu $Q i$ Gong yang memiliki konsep serupa dengan Senam GITA. Pada studi acak terkontrol terapi ini menunjukkan hasil yang menjanjikan untuk glukosa darah, trigliserida, total kolestrol, berat badan, IMT dan resistensi pada penderita diabetes mellitus tipe 2 (Putiri et al., 2017).

Latihan fisik dapat meningkatkan kontrol gula darah pada pasien diabetes mellitus tipe 2, mengurangi faktor resiko penyakit kardiovaskuler, berkontribusi pada penurunan berat badan, dan memperbaiki kualitas hidup (Colberg et al., 2016). Latihan fisik juga dapat meningkatkan 
Faletehan Health Journal, 7 (3) (2020) 155-161

www. journal.Ippm-stikesfa.ac.id/ojs/index.php/FHJ

ISSN 2088-673X | 2597-8667

pengambilan glukosa otot rangka. Pada penelitian acak telah menunjukkan latihan fisik selama 150 menit / minggu dikombinasi dengan diet dapat mengurangi resiko diabetes mellitus tipe 2 sebesar $58 \%$ pada populasi beresiko. Studi terbaru lainnya menunjukkan 6 bulan latihan fisik sedang menurunkan massa lemak viseral dan penurunakan kandungan trigliserida hati pada orang dengan DM tipe 2 dan program latihan fisik saja lebih efektif daripada program diet saja (Colberg et al., 2016).

Tabel 3. Hasil Rerata HbA1C Dalam 2 Kelompok Sebelum dan Sesudah Intervensi

\begin{tabular}{ccc}
\hline IMT & Mean+SD & P \\
\hline Senam & & \\
Pretest & $7.22 \pm 1.27$ & 0.000077 \\
Posttest & $6.95 \pm 1.32$ & \\
\hline Kontrol & & \\
Pretest & $6.78 \pm 1.84$ & 0.111 \\
Posttest & $6.84 \pm 1.91$ & \\
\hline
\end{tabular}

SD: Standard Deviation, GDP: Gula Darah Puasa

Tabel 3 menunjukkan hasil pre dan post tes HbA1C kelompok senam berbeda bermakna secara signifikan dengan $p$ value $0.000077(\mathrm{p}<0.05)$. Aktivitas fisik yang dilakukan oleh lansia dengan diabetes mellitus berupa senam GITA selama 12 minggu terbukti dapat menurunkan HbA1C dari $7.22 \pm 1.27$ menjadi $6.95 \pm 1.32 \%$.

Sejalan dengan penelitian ini, Senam GITA yang dilakukan selama 8 minggu dapat menurunkan kadar gula darah puasa pasien diabetes mellitus secara signifikan dengan $p$ value $<0.01$ (Amalia et al., 2020). Hasil analisis kualitatif berdasarkan wawancara semi-terstruktur dari responden yang telah melakukan Senam GITA diperoleh hasil: responden merasa relaks $(60 \%)$, energi meningkat (60\%) dan senam mudah dilakukan (70\%) (Amalia et al., 2020).

Penyakit diabetes mellitus dalam pandangan Traditonal Chinese Medicine diartikan akumulasi energi yang berlebihan pada pangkreas. Teknik gerakan pada Senam GITA membantu menyebarkan dan meratakan sirkulasi energi sehingga keseimbangan energi dalam tubuh dapat tercapai (Guo, 2017).

Senam GITA bila disejajarkan dengan metode perawatan kesehatan lain yang berasal dari Tiongkok seperti Tai Chi dan $Q i$ Gong juga memiliki efek dalam menurunkan HbA1C pada pasien diabetes mellitus. Pada penelitian ini diperoleh hasil penurunan kadar HbA1C secara signifikan dengan $p$ value $<0.01$. Pada empat belas penelitian tentang efek Tai Chi dengan HbA1C dibandingkan kelompok kotrol menunjukkan penurunan signifikan $\mathrm{HbA} 1 \mathrm{C}$ (MD - 0.88; 95\% CI $-1.45 \%$ hingga $-0.31 \% ; \mathrm{p}=0.002$ (Zhou et al., 2019). Pada 21 percobaaan dengan 1326 pasisen, studi meta-analisis $Q i$ Gong bila dibandingkan dengan kelompok tidak berolahraga memiliki efek signifikan pada gula darah puasa $(\mathrm{MD}=-0.99,95 \%$ CI $(-1.23,0.75), P<0.0001)$, kadar HbA1C (MD = $-0.84,95 \%$ CI $(-1.02,-0.65), P<0.0001)$, dan glukosa darah postprandial (MD $=-1.55,95 \% \mathrm{CI}$ $(-2.19,-0.91), P<0.00001)$ (Meng et al., 2018).

Tabel 4. Hasil Rerata Selisih IMT Dalam 2
Kelompok Sebelum dan Sesudah
Intervensi
\begin{tabular}{llll}
\multicolumn{2}{c}{ Kelompok } & $\mathrm{P}$ \\
\cline { 2 - 3 } Variabel & \multicolumn{2}{c}{ Kon } \\
\cline { 2 - 3 } & Senam & Kontrol & \\
\hline IMT & $0.63 \pm 0.17$ & $0.01 \pm 0.26$ & 0.000006 \\
\hline
\end{tabular}

Tabel 4 menunjukkan hasil rerata selisih IMT pada kelompok senam terjadi penurunan IMT yang lebih banyak sebesar $0.63 \pm 0.17 \mathrm{~kg} / \mathrm{m}^{2}$ bila dibandingkan dengan kelompok kontrolnya. Rerata selisih IMT pada kelompok senam berbeda bermakna secara signifikan dengan $p$ value 0.000006 ( $\mathrm{p}<0.05$ ). Hal ini menunjukkan bahwa senam GITA efektif dalam menurunkan IMT lansia dengan diabetes mellitus bila dibandingkan dengan kelompok kontrolnya.

Pengobatan Tradisional Tiongkok memandang tubuh secara keseluruhan dan mengenali pentingnya keterkaitan antara organ internalnya. Komunikasi antar bagian tubuh tidak hanya ditunjukkan melalui peredaran darah dan sistem saraf tetapi juga oleh jalur energi yang disebut meridian. Meridian ini yang membuat jaringan imternal energi terhubung dengan organ, jaringan, dan sel sebagai sistem informasi bioenergik (Putiri et al., 2017).

Gerakan senam GITA dapat meningkatkan pergerakan sel dalam tubuh dan menjadikannya lebih kuat, sehingga akan dapat melancarkan semua aliran energi dalam tubuh. Senam GITA menggunakan teknik penyinaran aliran energi. Teknik penyinaran tersebut berupa meningkatkan dan mengurangi tekanan pada bagian organ tubuh tertentu untuk mengembalikan kelancaran 
pergerakan $Q i$ (energi vital) sehingga semua aktivitas fungsional organ tubuh kembali normal dan seimbang. Jadi proses penyembuhan dengan teknik senam GITA menekankan perubahan gerakan energi vital atau aktivitas fungsional tubuh (Guo, 2017).

$\begin{array}{lll}\begin{array}{l}\text { Tabel 5. Hasil Rerata Selisih Kadar HbA1C } \\ \text { Dalam } 2 \text { Kelompok Sebelum dan } \\ \text { Sesudah Intervensi }\end{array} & \\ \begin{array}{clll}\multicolumn{2}{c}{\text { Selompok }} & \mathrm{P} \\$\cline { 2 - 3 } \text {$Variabel } & \multicolumn{2}{c}{\text { Kelompok }} & \\$\cline { 2 - 3 } & \text {$Senam } & \text { Kontrol } & \\ \hline \text { HbA1C } & 0.27 \pm 0.13 & 0.06 \pm 0.11 & 0.000006 \\ \hline\end{array}\end{array}$

Tabel 5 menunjukkan hasil rerata selisih kadar HbA1C pada kelompok senam lebih banyak sebesar $0.27 \pm 0.13$ dari kelompok kontolnya serta berbeda bermakna secara signifikan dengan $p$ value 0.000006 ( $\mathrm{p}<0.05)$. Hal ini menunjukkan bahwa senam GITA efektif dalam menurunkan kadar HbA1C lansia dengan diabetes mellitus bila dibandingkan dengan kelompok kontrolnya.

Senam GITA yang dalam bahasa Tiongkok disebut Dong Yi Gong memiliki arti sebagai berikut Dong artinya gerakan, $Y i$ artinya pikiran, dan Gong artinya kekuatan atau tenaga. Sehingga Dong $Y i$ Gong bermakna suatu gerakan dengan menggunakan kekuatan pikiran yang diperagakan dengan meradiasikan aliran energi (Guo, 2017).

Tubuh kita terdiri dari milyaran sel yang selalu bergerak terus menerus. Selama pergerakan membuka dan menutup, sel dapat berubah bentuk karena berbagai macam sebab, yang kemudian dapat menimbulkan berbagai macam penyakit. Selain itu, sel dapat memancarkan energi ke seluruh penjuru tubuh secara terus menerus selama gerakan membuka dan menutupnya sel. Energi ini saling mempengaruhi, meningkatkan, mengaktifkan, menggabungkan dan mempersatukan dengan lainnya sehingga dapat terjadi perubahan kondisi tubuh (Guo, 2017).

$Q i$ atau aktivitas energi pada dasarnya merupakan perubahan energi yang dihasilkan dari gerakan membuka dan menutupnya sel atau fenomena pergerakan energi. Jika sel tidak bergerak dan tidak memancarkan energi, maka tidak akan ada aktivitas keseimbangan energi. Teknik Gerakan Senam GITA menitikberatkan pergerakan energi untuk mencapai keseimbangan Yin dan Yang dalam tubuh. Teknik ini membantu meyebarkan dan meratakan sirkulasi energi dengan cara mengatur tekanan gelombang energi melalui posisi telapak tangan diletakkan lebih dekat dengan tubuh dan telapak tangan yang lain diletakkan lebih jauh dari tubuh. Tujuannya adalah menambah atau mengurangi tekanan di bagian tertentu sehingga keseimbangan energi dalam tubuh dapat tercapai (Guo, 2017).

\section{Simpulan}

Senam GITA selama 12 minggu terbukti efektif dalam menurunkan IMT dan HbA1C pada lansia dengan diabetes mellitus.

\section{Referensi}

Amalia, A. W., Gayatri, P. R., \& Tuna, H. (2020). Effectiveness of Gita Gymnastics on Blood Sugar Level Among Elderly With Diabetes Mellitus in Kediri. Healthy-Mu Journal, 4(1), 60. https://doi.org/10.35747/hmj.v4i1.539

American Diabetes Association. (2014). Standards of medical care in diabetes-2014. Diabetes Care, 37(SUPPL.1), 14-80. https://doi.org/10.2337/dc14-S014

BPS. (2017). Lanjut usia 2017. Statistik Penduduk Lanjut Usia 2017, xxvii + 258 halaman.

Colberg, S. R., Sigal, R. J., Yardley, J. E., Riddell, M. C., Dunstan, D. W., Dempsey, P. C., Horton, E. S., Castorino, K., \& Tate, D. F. (2016). Physical activity/exercise and diabetes: A position statement of the American Diabetes Association. Diabetes Care, 39(11), 2065-2079. https://doi.org/10.2337/dc16-1728

Dwipayanti, N. M. A., Nariata, I. W., \& Aryana, I. G. P. S. (2020). Diabetes mellitus control among elderly patients at geriatric polyclinic of karangasem district hospital, Bali, Indonesia: A preliminary study. Bali Medical Journal, 9(1), 279-285. https://doi.org/10.15562/bmj.v9i1.1664

Ferriolli, E., Pessanha, F. P. A. S., \& Marchesi, J. C. L. S. (2014). Diabetes and exercise in the elderly. Medicine and Sport Science, 60, 122129. https://doi.org/10.1159/000357342

Gray, N., Picone, G., Sloan, F., \& Yashkin, A. (2015). The Relationship between BMI and Onset of Diabetes Mellitus and its Complications. South Med J., 108(1), 29-36. https://doi.org/10.14423/SMJ.000000000000 0214. The

Guo, Z. C. (2014). Introduction to body space medicine. Handbook of Traditional Chinese Medicine,

1271-1282. 
Faletehan Health Journal, 7 (3) (2020) 155-161

www. journal.Ippm-stikesfa.ac.id/ojs/index.php/FHJ

https://doi.org/10.1142/9789814293839_003 5

Guo, Z. C. (2017). Teknik Senam GITA untuk Penyembuhan Diri Sendiri Dong Yi Gong. Yayasan Ilmu Kesehatan Ruang Tubuh Indonesia.

Hayes, A. J., Leal, J., Gray, A. M., Holman, R. R., \& Clarke, P. M. (2013). UKPDS Outcomes Model 2: A new version of a model to simulate lifetime health outcomes of patients with type 2 diabetes mellitus using data from the 30 year united kingdom prospective diabetes Study: UKPDS 82. Diabetologia, 56(9), 1925-1933. https://doi.org/10.1007/s00125-013-2940-y

Kautzky-Willer, A., Harreiter, J., \& Pacini, G. (2016). Sex and gender differences in risk, pathophysiology and complications of type 2 diabetes mellitus. Endocrine Reviews, 37(3), 278-316. https://doi.org/10.1210/er.20151137

Kemenkes

RI. (2018). Laporan_Nasional_RKD2018_FINAL.pdf. In Badan Penelitian dan Pengembangan Kesehatan (p. 198). http://labdata.litbang.kemkes.go.id/images/do wnload/laporan/RKD/2018/Laporan_Nasiona 1_RKD2018_FINAL.pdf

Kirkman, M. S., Briscoe, V. J., Clark, N., Florez, H., Haas, L. B., Halter, J. B., Huang, E. S., Korytkowski, M. T., Munshi, M. N., Odegard, P. S., Pratley, R. E., \& Swift, C. S. (2012). Diabetes in older adults. Diabetes Care, 35(12), 2650-2664. https://doi.org/10.2337/dc12-1801

Meng, D., Chunyan, W., Xiaosheng, D., \& Xiangren, Y. (2018). The Effects of Qigong on Type 2 Diabetes Mellitus: A Systematic Review and Meta-Analysis. Evidence-Based Complementary and Alternative Medicine, 2018. https://doi.org/10.1155/2018/8182938

Mordarska, K.; Godziejewska-Zawada, M. (2017). Diabetes in the elderly. Menopause Review,
$16(2)$,

38-43. https://doi.org/10.1684/stv.2010.0503

Pahlawati, Annisa; Nugroho, P. S. (2019). Hubungan Tingkat Pendidikan dan Usia dengan Kejadian Diabetes Mellitus di Wilayah Kerja Puskesmas Palaran Kota Samarinda Tahun 2019. Borneo Student Research, 1(1), 1-5. https://journals.umkt.ac.id/index.php/bsr/artic le/view/479/273

PERKENI. (2019). Pedoman pengelolaan dan pencegahan diabetes melitus tipe 2 dewasa di Indonesia 2019. In Perkumpulan Endokrinologi Indonesia (pp. 1-117). https://pbperkeni.or.id/wpcontent/uploads/2020/07/PedomanPengelolaan-DM-Tipe-2-Dewasa-diIndonesia-eBook-PDF-1.pdf

Pratiwi, T. A., Lubis, R., \& Mutiara, E. (2018). Pengaruh Obesitas terhadap Kejadian Diabetes Mellitus pada Wanita Usia Subur di RSUD Dr. Djoelham Binjai Tahun 2017. Journal of Healthcare Technology and Medicine, 4(1), 1-10. https://doi.org/10.33143/jhtm.v4i1.161

Putiri, A., Close, J., Lilly, H., Guillaume, N., \& Sun, G.-C. (2017). Qigong Exercises for the Management of Type 2 Diabetes Mellitus. Medicines, $4(4), \quad 59$. https://doi.org/10.3390/medicines4030059

Siddiqui, S. (2018). Obesity and diabetes: interrelationship. Advances in Obesity, Weight Management \& Control, 8(2), 155-158. https://doi.org/10.15406/aowmc.2018.08.002 33

Zhou, Z., Zhou, R., Li, K., Zhu, Y., Zhang, Z., Luo, Y., \& Luan, R. (2019). Effects of tai Chi on physiology, balance and quality of life in patients with type 2 diabetes: A systematic review and meta-analysis. Journal of Rehabilitation Medicine, 51(6), 405-417. https://doi.org/10.2340/16501977-2555 